\title{
Experimental Design and Analysis of Camshaft by Using Aluminium Alloy(8090) and Silicon Carbide (Sic) Metal Matrix Composite
}

\author{
M.Gokul ${ }^{1,}$ S.Iyyappan ${ }^{2}$, K.Bhuvanesh ${ }^{3}$, S.Gokulakannan $^{4}$,. \\ ${ }^{I}$ Assistant Professor,Mechanical Engineering,Muthayammal Engineering College, Rasipuram, Tamil Nadu, \\ India \\ 2,3,4. Department of Mechanical Engineering,Muthayammal Engineering College, Rasipuram, Tamil Nadu, India
}

\begin{abstract}
Metal matrix composite (MMC) material is one which contains two or more materials with different physical and chemical properties with two constituent parts, one being a metal and other may be metal, ceramic or fiber. Due to their light in weight, high strength and high hardness, among various MMC"s, aluminium $M M C$ is the most widely used. The wide range of availability of aluminium has made it an important material for manufacturing many components. An aluminium alloy which has low tensile strength and hardness is been composited with other materials to improve its properties and reduce its drawbacks. Aluminium is been composited with silicon carbide that drastically increases the properties. In this study we developed aluminium metal matrix hybrid composite by reinforced Aluminium 8090 alloy with silicon carbide (SiC) by method of stir casting. Maintaining a Constant amount of aluminium and silicon carbide is varied to obtain a two different compositions of (AlSi) composites. The mechanical properties such tensile strength hardness are studied. The composites are tested for their flexural and impact properties and the result shows that all the properties of hybrid composite are superior than base metal.
\end{abstract}

Keywords: Metal matrix composite,Aluminium alloy 8090 , silicon carbide (sic ), Stir casting process.

\section{Introduction}

A composite material is a combination of two or more chemically distinct materials to form a stronger material. The term "composite" broadly refers to a material system which is composed of a discrete constituent (the reinforcement) distributed in a continuous phase (the matrix), and which derives its distinguishing characteristics from the properties of its constituents, from the geometry and architecture of the constituents, and from the properties of the boundaries (interfaces) between different constituents. Composite materials are usually classified on the basis of the physical or chemical nature of the matrix phase, e.g., polymer matrix, metal-matrix and ceramic composites MMC (Metal matrix composites) are metals reinforced with other metal, ceramic or organic compounds.

Reinforcements are usually done to improve the properties of the base metal like strength, stiffness, conductivity, wear and corrosive resistance etc... Aluminum, Silicon, Copper, Titanium, Magnesium, and Nickel metals are widely used for preparation of metal matrix in composites materials .In Metal Matrix Composites (MMCs), Aluminum and its alloys have attracted most attention as base metal in metal matrix composites because of its low density, low weight, high strength, superior malleability, easy machining, excellent corrosion resistance and good their mal and electrical conductivity, etc. In recent years, Al based composite materials have gained significance in aerospace, automotive and structural applications due to their enhanced mechanical properties and good stability at high temperature. The various reinforcements used are Silicon Carbide, Aluminium Oxide, Titanium carbide, Boron Carbide, etc.

$\mathrm{SiC}$ reinforcement increases the tensile strength, hardness, density and wear resistance of $\mathrm{Al}$ and its alloy. The interfacial reaction between the materials is also important because if the load carrying transferred to the interface, it will affect the mechanical properties of the composite material. The way of reinforcement also changes the physical properties like wear resistance, hardness, thermal conductivity. The reinforcement can be either continuous or discontinuous. The MMC's prepared by discontinuous process are isotropic and by continuous process are anisotropic structure. The anisotropic structure occurs because the fibers such as carbon fibers and monofilament wires embedded in to the matrix in particular direction. For processing of AMMCs at industrial scale, the processing operations classified in to two main groups. Liquid state processes and solid state processes. Stir casting, compo casting and squeeze casting spray casting and in situ (reactive) processing; ultrasonic assisted casting comes under the liquid state process. For discontinuous metal matrix composites various techniques are available. Among them stir casting method is generally preferred. Its advantages lie in its simplicity, flexibility and applicability to large quantity of production. It is also attractive because of minimized final cost of the product. It also allows very large sized components to be fabricated. In the stir casting method, 
there are several factors that need considerable attention, including the difficulty of achieving a uniform distribution of the reinforcement. The composites, before fabrication process, are heat treated to an under aged condition as the materials can be shaped more easily and after fabrication, these materials are heat treated to the peak aged condition so as to provide improved mechanical properties.

\section{A. Material}

\section{Experimental Details}

In this work, matrix material is aluminum while Silicon carbide in powder form are reinforced with the varying volume fractions as reinforcement. Silicon Carbide is one of the widely used ceramic particles due to its properties like high hardness and low coefficient of thermal expansion $\left(4.6 \times 10-6 /{ }^{\circ} \mathrm{C}\right)$. It is used in automotive brakes and clutches. The properties of the matrix and the reinforcements are shown in table 1

Table 1: Properties of $\mathrm{Al}, \mathrm{SiC}$

\begin{tabular}{|l|l|ll|}
\hline Properties & $\begin{array}{l}\text { Aluminium } \\
\text { alloy } 8090\end{array}$ & Silicon carbide \\
\hline Tensile strength & $450 \mathrm{Mpa}$ & $240 \mathrm{Mpa}$ & \\
\hline $\begin{array}{l}\text { Thermal } \\
\text { conductivity }\end{array}$ & $95.3 \mathrm{~W} / \mathrm{mK}$ & $120 \mathrm{mK}$ \\
\hline
\end{tabular}

\section{B.Stir casting process}

Stir casting process is used to fabricate composite consists of an induction furnace with three mild steel stirrer blades. Here, the reinforcements are distributed into molten aluminium matrix by mechanical stirring. During preheating stage, the reinforcements are heated separately nearer to main process temperature of $400^{\circ} \mathrm{C}$ while aluminium is melted in a separate crucible at a temperature of $830^{\circ} \mathrm{C}$. Now, the preheated reinforcements are mechanically mixed with the molten aluminium below their melting temperature. Then, the mixture is poured into the die and allowed to solidify. The weight percentage of the matrix and the reinforcements for different samples are shown in table 2.

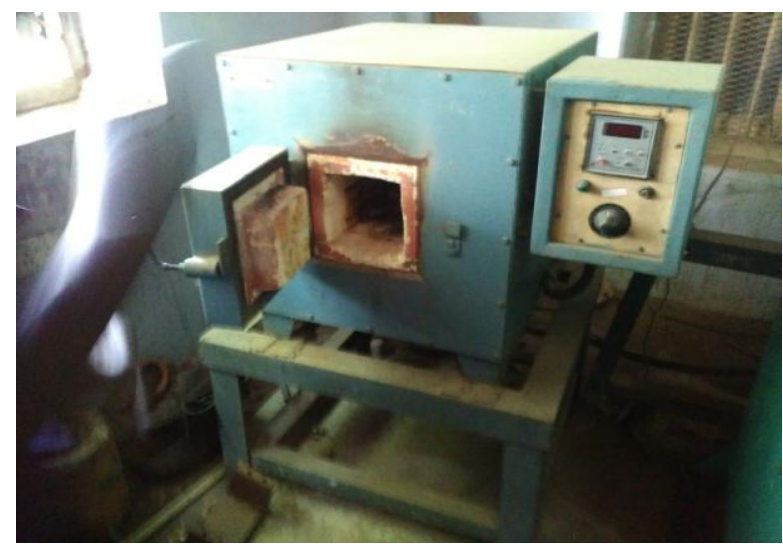

Reinforcement Preheat Setup

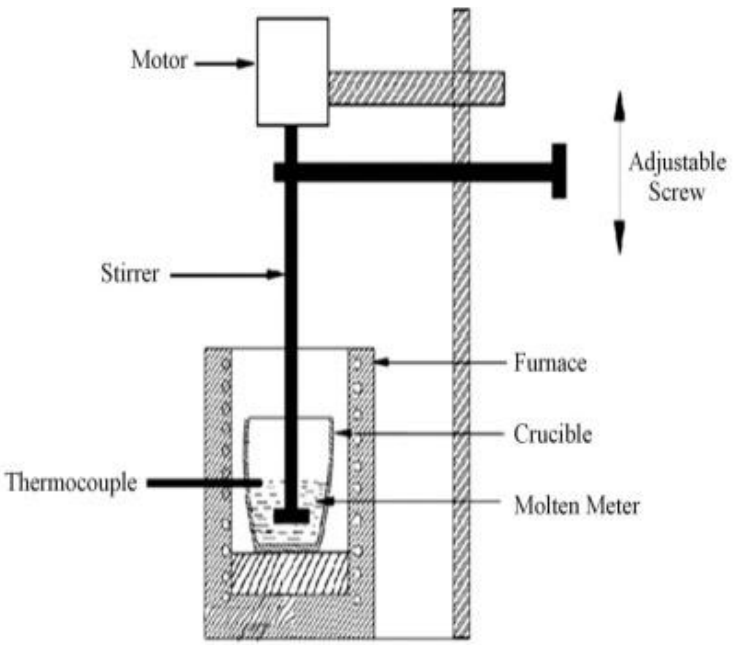

Reinforcement process 
Table 2: Composition of matrix and reinforcement in wt $\%$

\begin{tabular}{|l|l|l|}
\hline Samples & Aluminium in\% & Silicon Carbide in\% \\
\hline 1. & 97 & 3 \\
\hline 2. & 93 & 7 \\
\hline
\end{tabular}

\section{Testing}

The following tests are performed on the aluminium metal matrix composite samples to find the influence of reinforcements on their mechanical properties. Table 3 shows various tests.

Table 3 Various Tests

\begin{tabular}{|l|l|l|l|}
\hline Test number & Name of the test & Purpose & Machine used \\
\hline 1. & Tensile test & $\begin{array}{l}\text { Machined specimen is placed } \\
\text { in thesting machine and } \\
\text { load is applied. A strain gage } \\
\text { or extensometer is used to } \\
\text { measure elongation }\end{array}$ & $\begin{array}{l}\text { Universal testing } \\
\text { machine (UTM) }\end{array}$ \\
\hline 2. & $\begin{array}{l}\text { Hardness is a measure of how } \\
\text { resistant solid matter is to } \\
\text { various kinds of permanent } \\
\text { shape change when a a and and test } \\
\text { compressive force is applied }\end{array}$ & $\begin{array}{l}\text { Universal testing } \\
\text { machine (UTM) }\end{array}$ \\
\hline
\end{tabular}

\section{Results and discussions}

The following tests are performed on the aluminium metal matrix composite samples to find the influence of reinforcements on their mechanical properties. Table 4 shows various tests.(For speicemen 1)

Table 4 .Various Tests for S-1

\begin{tabular}{|l|l|}
\hline Property & Material \\
\hline Tensile strength & $135 \mathrm{Mpa}$ \\
\hline Yield stress & $114.29 \mathrm{Mpa}$ \\
\hline Elongation & $22.36 \%$ \\
\hline Hardness & $58 \mathrm{HBW}$ \\
\hline
\end{tabular}

The following diagram shows the total deformation

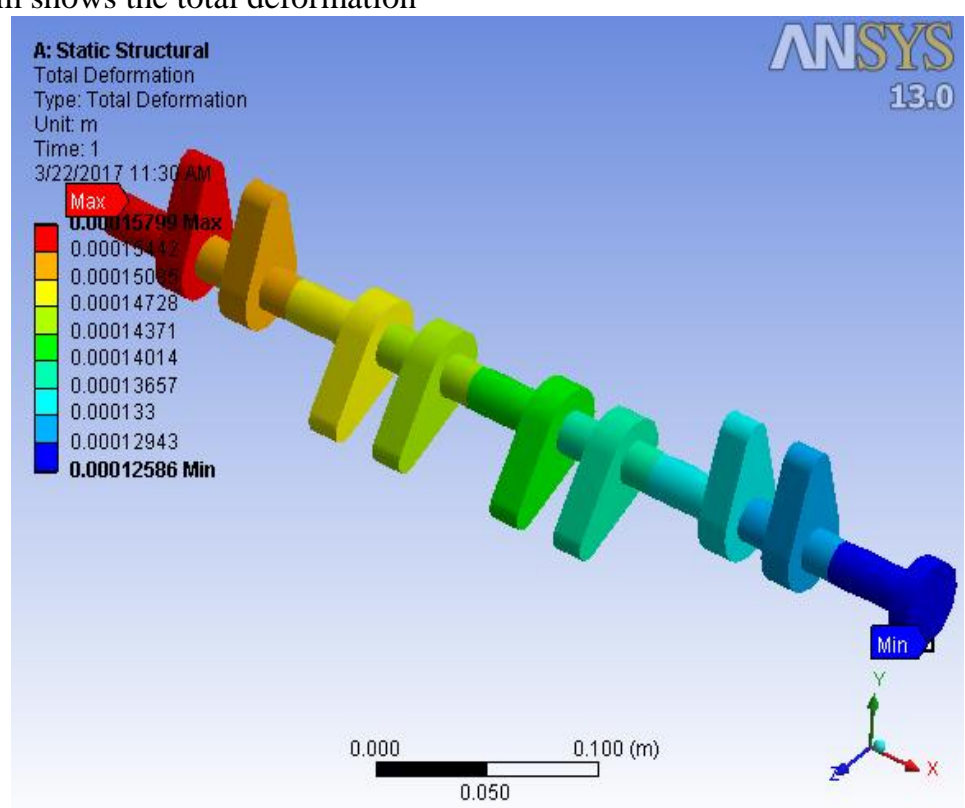


The following diagram shows the equivalent stress

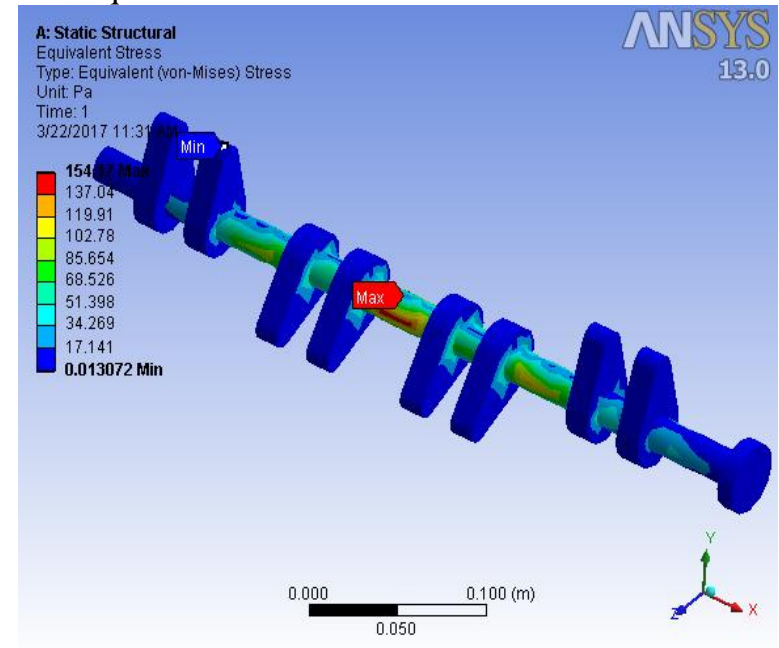

The following diagram shows the equivalent elastic strain

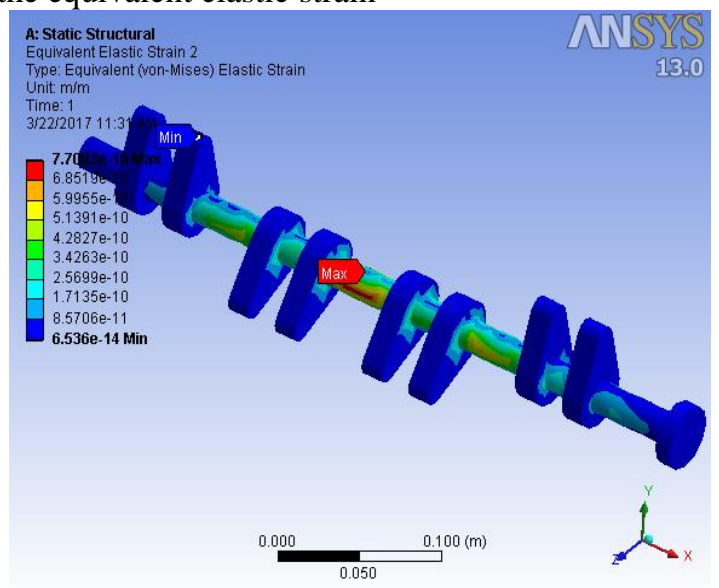

The following tests are performed on the aluminium metal matrix composite samples to find the influence of reinforcements on their mechanical properties. Table 5 shows various tests.(For speicemen 2)

Table 5 .Various Tests for S-2

\begin{tabular}{|l|l|}
\hline Property & Material \\
\hline Tensile strength & $138.49 \mathrm{Mpa}$ \\
\hline Yield stress & $116.99 \mathrm{Mpa}$ \\
\hline Elongation & $17.68 \%$ \\
\hline Hardness(10/1000) & $63 \mathrm{HBW}$ \\
\hline
\end{tabular}

\section{Conclusions}

The above review for the aluminum based metal matrix composite leads to the following conclusions:

1. Finally, We have concluded that the composition of Al (93\%) + SIC (7\%) is having more efficient yield and tensile strength, hardness then the composition of $\mathrm{Al}(97 \%)+\mathrm{SIC}(3 \%)$. So that this composite material can use in cam shaft for more efficiency and life period.

2. Stir casting process is well suited and economical for the preparation of AMMC's with desired properties.

3. By increasing the wt $\%$ and decreasing the particle size of reinforced material in the aluminium composites the hardness, tensile strength increases.

\section{Reference}

[1]. V.Rama koteswara Rao International Journal of Scientific \& Engineering Research, Volume 7, Issue 2, February-2016 742 ISSN $2229-5518$

[2]. S.Vijayakumar1 SSRG International Journal of Material Science and Engineering (SSRG-IJMSE) volume 2 Issue6 November to December 2016

[3]. Chen P (1992) High- performance machining of SiC Whisker Reinforced Aluminium Composite by Self Propelled Rotary Tools. CIRP Ann 41:59-62 
[4]. M.Gokul, Analysis and Fabrication of Mechanical Properties of Banana and Sisal Hybrid Composites. International Journal of Innovative Research in Science,Engineering and Technology Vol. 4, Special Issue 6, May 2015

[5]. A. Kalaiyarasan, P. Ramesh., P. Paramasivam., Study of Advanced Composite Materials in Aerospace Application., International Journal of Scientific Research in Mechanical and Materials Engineering Volume 1 | Issue 1 25-34

[6]. Suresh S, Mortensen A, Needleman A (1993) Fundamentals of metal matrix composites. Butterworth-Heinemann, pp 3-23

[7]. Vijaya Ramnath B, Elanchezhian C, Annamalai RM, Aravind S, Sri AnandaAtreya T, Vignesh V, Subramanian C (2014)

[8]. M. Gokul, Aluminum Based Metal Matrix Composites : A Review Influence of Reinforced Particles; Techniques; Factors Affecting the Composite, , International Journal of Scientific Research in Mechanical and Materials Engineering Volume 1 | Issue 1

[9]. Aluminium metal matrix composites - a review. Rev Adv Mater Sci 38:55-60

[10]. Sun Y, Lyu Y, Jiang A (2014) Fabrication and characterization of aluminum matrix fly ash chemosphere composites using different stir casting routes. Jr Materi Res 29:260-266

[11]. Harish Garg K, KetanVerma AM, Kumar R (2012) Hybrid metal matrix composites and further improvement in their maChinability. Int J Latest Res Sci Technol 36:2278-5299

[12]. Schneider Y, Soppa E, Kohler MR (2011) Numerical and experimental investigations of the global and local behaviour of a (6061)/ $/ \mathrm{Al}_{2} \mathrm{O}_{3}$ metal matrix composite under low cycle fatigue. Proced Eng 10:1515-1520 